\title{
LA FILOSOFÍA DE IGNACIO ELLACURÍA: UNA NUEVA TEORÍA CRÍTICA CON IMPLICACIONES PARA LA PEDAGOGÍA
}

\author{
MARCOS SANTOS GÓMEZ \\ Universidad de Granada
}

\begin{abstract}
RESUMEN: En primer lugar, exponemos sistemáticamente la filosofía de la realidad histórica de Ignacio Ellacuría incluyendo los comentarios más relevantes por parte de algunos autores tras una revisión bibliográfica de fuentes secundarias en las bases de datos más importantes. Se incide especialmente en lo que la propuesta de Ellacuría tiene de alternativa al pensamiento postmoderno y a la modernidad más dogmática. Su metafísica de raigambre zubiriana lo dota de una singular capacidad para ejercer la crítica social de los contenidos dados en la historia, desde una normatividad inmanente, sin los problemas del recurso a trascendentales exteriores a la propia historia, pero sin que lo normativo se confunda con lo dado. La clave son las «posibilidades» que alberga la realidad histórica desde las cuales se juzga el presente. En segundo lugar extraemos unas implicaciones para la educación y la pedagogía, así como proponemos una breve conclusión que enfatiza el carácter no logrado y siempre abierto de la historia.
\end{abstract}

PALABRAS CLAVE: Ellacuría, Filosofía de la Liberación, Realidad histórica, realismo, metafísica, materialismo, educación.

\section{The Philosophy of Ignacio Ellacuria: a new Critical Theory with implications for pedagogy}

\begin{abstract}
First, I present systematically the philosophy of historical reality of Ignacio Ellacuria, including comments of the most relevant works by some authors, after a review of secondary sources in major databases. We emphasize particularly as the proposal of Ellacuría is a philosophical alternative to postmodern thought and to the most dogmatic modernity. His zubirian metaphysical roots give it a unique capacity to do an immanent social critique of the content given in the History. This is possible without going «outside» history looking for external transcendentals; but also without the conservative acceptance of the factual contents of history. The key are the "possibilities", that the historical reality keeps in itself, from which, the present is judged. Second, I draw some implications for education and pedagogy, and I write a brief conclusion which emphasizes the open character of history.
\end{abstract}

KEY WORDS: Ellacuría, Philosophy of Liberation, Historical Reality, realism, metaphysics, materialism, education.

\section{INTROdUCCIÓN. LA PERSPECTIVA DEL EXCLUIDO EN LA FILOSOFÍA}

Como señalamos en un anterior trabajo ${ }^{1}$, algunos autores mantienen que recoger la experiencia de los oprimidos dentro del discurso filosófico es, en primer lugar y sobre todo, un requerimiento epistemológico. En una línea de notables semejanzas con el planteamiento de aquel trabajo, vamos a destacar que también se han elaborado otros proyectos filosóficos como la Filosofía de la Liberación latinoamericana ${ }^{2}$. En América

1 SAntos, M. «Pedagogía y memoria. Educar a partir del recuerdo de los vencidos», Pensamiento: Revista de Investigacion e Informacion Filosofica, 68, 255 (2012), pp. 107-120.

2 Cfr. Beorlegui, C. "Corrientes actuales de la Filosofía de la Liberación», Diálogo Filosófico, 65 (2006), pp. 196-223. También, Horacio Cerutti nos presenta una visión 
Latina los esfuerzos, dentro de esta perspectiva filosófica, han sido muchos y muy ricos. De hecho, la Filosofía de la Liberación latinoamericana intenta situarse así expresamente, en la perspectiva de los excluidos: «Como en el clima postmoderno de la filosofía contemporánea es muy dificultoso defender y justificar principios universales, la filosofía de la liberación tiene que emprender la tarea de intentar una fundamentación de una ética universalista desde la perspectiva de los empobrecidos y excluidos» ${ }^{3}$. Esto es plenamente recogido por el pensamiento de Ignacio Ellacuría, que basa su posicionamiento en el mencionado requerimiento epistemológico. «Para Ellacuría la fundamentación teórica de la opción por las mayorías y los pueblos oprimidos radica en que son ellos y su realidad objetiva el lugar adecuado para apreciar la verdad o falsedad del sistema» ${ }^{4}$.

\section{LA REALIDAD HISTÓRICA}

Ignacio Ellacuría intenta situarse exclusivamente en un ámbito filosófico e inmanente para pensar la historia. Concede una importancia central a lo que denomina «realidad histórica», a la que entiende como «la realidad física y metafísica del proceso histórico en cuanto tal y no la determinación de las cosas concretas que ocurren en ese proceso ${ }^{5}$. En este sentido, la historia cumple una función trascendental en cuanto que determina en la persona sus posibilidades de verdad y de sentido último. Se trata de un realismo de raigambre zubiriana en el que la historia es lo que hace humano al animal humano. La tarea fundamental de la Filosofía de la realidad histórica que él funda y desarrolla ${ }^{6}$ es poner de manifiesto la realidad histórica como la manifestación última de la realidad, lo cual es según él el objeto propio de la filosofía. Ellacuría desarrolla el concepto de «realidad histórica» como la síntesis de la dialéctica hegeliano-marxista y de la radicalización del realismo de raigambre escolástica de Xavier Zubiri. La realidad histórica es física, no conceptual, material y no ideal, concreta y no abstracta. La realidad histórica abarca los momentos materiales, biológicos, individuales y sociales de la realidad que confluyen en el hombre y en lo personal, en la historia como dimensión donde se realiza lo personal. Y cuando se considera en su totalidad dicha realidad histórica, como una estructura dinámica y diferenciada de sus momentos, funciones y relaciones, la realidad histórica constituye un sistema trascendental-metafísico intramundano ${ }^{7}$.

personal bien fundamentada, a partir de un balance exhaustivo de la producción filosófica de esta corriente. Expresa y argumenta su particular concepción al hilo del comentario y lectura crítica de los autores más representativos. Vid. Cerutti, H. Filosofía de la liberación latinoamericana, FCE, México D. F., 2006. Sobre la producción actual de estos filósofos, vid. Romero, J. M. «La Filosofía de la Liberación: recientes aportaciones bibliográficas», Diálogo Filosófico, 65 (2006), pp. 225-232.

3 Samour, H. «El significado de la filosofía de la liberación hoy», Diálogo filosófico, 65 (2006), pp. 233-252, p. 235.

4 SAmour, H. Voluntad de liberación. La filosofía de Ignacio Ellacuría. Granada, Comares, 2003, p. 258.

5 Ellacuría, I. Cursos universitarios. San Salvador, UCA Editores. 2009, p. 118.

6 Ellacuría, I. Filosofía de la realidad histórica. San Salvador, UCA Editores. 1999.

7 Mejido C, M. «Ignacio Ellacuria's Philosophy of Historical Reality: Beyond the Hegelian-Marxian Dialectic and the Zubirian Radicalization of Scholastic Realism», Philosophy and Theology: Marquette University Quarterly, 18, 2 (2006), pp. 287-318. Al poco tiempo de aparecer publicadas póstumamente las obras filosóficas de Ellacuría Filosofía de 
Así, la historia no surge de un hegeliano Espíritu absoluto, si nos ceñimos a la realidad intramundana, sino de los individuos personales que forman un cuerpo social y una especie. Hay aquí una concepción estrictamente relacional que se diferencia de la sustantivación del proceso en Marx o Hegel. En éstos, los individuos padecen la historia, más que hacerla. Para Zubiri, sin embargo, el individuo está inmerso en la historia pero también la hace ${ }^{8}$. Esto no quiere decir que la historia sea eminentemente subjetividad, porque aunque existe el intervenir y obrar individual en la historia, lo social y las determinaciones existen, evidentemente, en la biografía personal. En realidad, no pueden separarse ambos ámbitos 9 .

Los individuos no son meros accidentes de un proceso omniabarcante y acaparador que los subsume y anula (Hegel). En la historia, cuentan los individuos, en cuanto pueden optar con un cierto margen de libertad. Esto siempre dentro de unas determinaciones. «La historia, en efecto, implica un sistema de posibilidades, que en cada momento tiene una altura procesal precisa y frente al cual las personas individuales se encuentran en una determinada situación ${ }^{10}$. Se habla de historia si se habla de posibilidades, más que de necesidad, lo cual no implica que el individuo carezca de elementos contextuales y limitadores, desde la propia animalidad a otros niveles de circunstancias. Desde la perspectiva de Ellacuría, lo histórico no es ni pura naturaleza ni pura libertad, sino lo que Zubiri llama «impersonalidad». "Zubiri contrapone aquí generalidad e impersonalidad: no es lo general lo que mueve la historia, sino lo personal reducido a impersonal. (...) la historia no está por encima de los individuos como una generalidad suya, sino por bajo de ellos como resultado de una despersonalización ${ }^{11}$. Es decir, hay historia porque hay personas, y no al revés.

El realismo de Zubiri está en que «sólo religado a lo absoluto de la realidad se hace ab-soluta la vida personal del hombre» ${ }^{12}$. Es decir, la persona sólo encuentra un ámbito de realización histórico, o sea, inmerso en su realidad histórica. Por ello, cabe hablar de alienación, en cuanto una realidad que domina a la persona y la anula, o de la historia como capacitación para ser persona. Lo histórico puede tender, en consecuencia, de manera peligrosa a lo general, por su carácter impersonal, pero también puede, si no pierde el contacto con lo personal como procedencia, capacitar y posibilitar el desarrollo de lo personal. «al ser estrictamente algo que tiene que ver con la persona, algo de la persona, está en disposición de personalizar, de capacitar a las personas para ir realizando más y más su ser absoluto» ${ }^{13}$. Así, la historia es un sistema de posibilidades ofrecidas a los individuos y grupos, o al cuerpo social entero, algunas de las cuales tienen que ver con el recuerdo del pasado. Pero siempre habrá historia si es que lo es para sujetos de la

la realidad histórica $(O p$. Cit.) y los volúmenes teológicos Ellacuría, I. y Sobrino, J. Mysterium Liberationis. Conceptos fundamentales de la teología de la liberación, UCA Editores, San Salvador, 1993, en el siguiente trabajo se recogía una aproximación al pensamiento del filósofo sobre la realidad histórica: MARTínez, J. A. "Filosofía e Historia Según I. Ellacuría», Pensamiento: Revista de Investigación e Información Filosófica, 51, 199 (1995), pp. 149-153.

8 Ellacuría, I., Filosofía de la realidad... op. cit., p. 122.

9 Ídem.

$10 \quad$ Ibíd., p. 123.

11 Ídem.

12 Ibíd., p. 125.

13 Ibid., p. 126. 
historia. "sin ese carácter de subjetualidad genitiva, sin este ser historia-de, la historia no es real como historia» ${ }^{14}$.

A partir de todo esto, el sentido de la historia ha de ser buscado intramundanamente, sin que se conciba al modo de algo que anule a la propia historia. Así, la contraposición con lo eterno como sentido puede oscurecer la realidad de la historia. «ni el más allá de la historia, ni la historia sin historia son el mejor de los caminos para buscar el posible sentido de la historia que se afirma a sí misma como historia» ${ }^{15}$. No debe extraerse el sentido de lo posterior a la historia, sino de ella misma. Incluso teológicamente, puede abordarse de esta manera, entendiendo la eternidad no como negación de la historia, sino como su superación a partir de ella misma. O considerar la eternidad como la absolutez de la historia misma, absolutez que le es propia, como hemos señalado. Esto implica una concepción de eternidad como simultaneidad (no temporal), simultaneidad que respeta la transcurrencia. «La historia tiene, por tanto, algo que ver con su fin, pero el fin de la historia no es aquí ni la negación de lo histórico ni la negación de la historia; es ese momento de absoluto intranscurrente, que el hombre ha de vivir transcurrentemente ${ }^{16}$.

Así pues, la realidad es un enorme proceso de realización del todo. Un todo sustentado por la respectividad de lo real, y que constituye una unidad «respectiva y dinámica». Es en este fondo en el que se va definiendo el sentido de la historia. Se trata de un nivel superior que integra y eleva también a lo natural, que se puede decir continúa su evolución históricamente, en la medida en que el obrar del hombre refluye sobre lo natural. Así pues, hay una trascendentalidad del orden abierto de la historia en el que se va realizando el hombre. De hecho, la apertura de la historia se vincula con la apertura de la persona. Ellacuría considera una realidad lo personal. Por eso, la praxis histórica «es un dinamismo creacional o cuasi-creacional, que lleva a la realización de la persona en tanto que persona y, por tanto, a una planificación de la realidad, de la verdad, de la bondad y de la belleza, que solo se actualizan formalmente en la praxis fundamental que es la vida humana» ${ }^{17}$.

Así, la personalización también presupone la historia, que es propiamente lo que la posibilita. La historia va proporcionando el material de capacidades para que la persona se realice. Así, no hay un sujeto abstracto ni debe entenderse la persona como algo abstraído de la historia y exento de materialidad, sino que al contrario, la persona requiere de lo que va hallando en la historia para actuar y hacerse. Por eso, «Es (...) la historia como sistema de posibilidades, a donde deben volverse los hombres que buscan humanizar la humanidad, que buscan el que todos tengan una vida más plena; del sistema de posibilidades ofrecido penderá en gran parte el tipo de humanidad que a los hombres les es dado desarrollar» ${ }^{18}$. Así, el hombre va creándose en función de las capacidades que le proporciona su realidad histórica, a la cual también va transformando. La historia sería, en este sentido, el sistema de posibilidades con que se encuentra el hombre en un tiempo dado. Lo que señalaría un sentido positivo en el proceso es, precisamente, si se da el aumento del grado de libertad y de posibilidades de realización.

La historia se va totalizando, es un principio de totalidad, en el que las partes no pierden su singularidad, frente a Hegel. Antes bien, la totalidad exige la diversidad,

$14 \quad$ Ibid., p. 127.

15 Ibid., p. 128.

16 Ibid., p. 129.

17 Ibid., p. 132.

18 Ídem. 
pues es una totalidad sistemática y estructural en la que los elementos se posicionan estática y dinámicamente. Es una totalización procesual que no elimina la libre optatividad humana. En este dinamismo ocurre una cierta revelación, que en Zubiri tiene un sentido teológico. En cualquier caso, es una revelación que no debe interpretarse como desvelamiento sino como actualización. Lo que propiamente se revela en la historia es la realidad. «Sólo en la historia y por la historia sabremos lo que es la realidad, y sólo en la historia y por la historia sabremos lo que es el hombre. Y esto no primariamente porque vayan aumentando los conocimientos del hombre, sino porque la realidad misma va dando más de sí y porque el hombre mismo, el género humano, va haciéndose más real, en virtud del acrecentamiento de sus capacidades» ${ }^{19}$.

Ignacio Ellacuría, desde su planteamiento zubiriano, afirma que el hombre se realiza como animal de realidades apropiándose de propiedades. Este crear realidad, que constituye lo propio del hombre como especie, es lo que lo convierte en un ser esencialmente moral $^{20}$. Lo moral apuntaría a este ámbito de la apropiación de propiedades y por tanto reconstrucción de la realidad por parte del hombre. Es decir, el hombre se construye a sí mismo, actualizando posibilidades que cristalizan en capacidades que permiten, a su vez, un nuevo juego de posibilidades. Porque el hombre resuelve sus problemas, según Ellacuría, no sólo mediante una inmersión en la realidad, como el resto de los animales, sino como una modificación de su realidad ${ }^{21}$. Éste es el modo de ser del animal humano en el que también tiene sentido entender la educación. Ética, historia y educación se hallarían estrechamente vinculadas a partir del pensamiento de Ellacuría. Porque es en la historia donde se puede dar lo opcional dentro de los límites que otorga la historia misma, en esa combinación de libertad y determinismo que caracteriza a la actividad humana, y la educación emancipatoria habría de facultar para este optar propio del hombre.

\section{REALIDAD MORAL}

El hombre resuelve sus problemas no sólo mediante una inmersión en la realidad, como el resto de los animales, sino como una modificación de su realidad. Hay pues consecuencias metafísicas en este quehacer del hombre en cuanto se constituye realidad. Lo moral parte de esta relación peculiar del hombre con el todo real y presupone la captación inteligente de dicho todo ${ }^{22}$. Es lo que señala Conill que es el hacerse cargo de la realidad. Este hacerse cargo es al modo responsable que entiende las implicaciones más allá de la actitud meramente contemplativa o interpretativa. Es un hacerse cargo activo, operativo, por lo que se habla también de cargar con la realidad. Estos dos momentos (hacerse cargo de la realidad y cargar con ella) conducen al encargarse de la realidad como donde podemos identificar una forma de deber de tipo moral. Se trata, creo, de las repercusiones que lo que hace el hombre tienen en la realidad. Esta sería la forma en que prosigue el proceso de hominización, según Ellacuría, y el modo en que

19 Ibid., p. 140.

20 Conill, J. «Las líneas de fundamentación en la propuesta ética de Ignacio Ellacuría», en Senent de Frutos, J. A. y Mora, J. (dirs.) Ignacio Ellacuría 20 años después. Actas del Congreso Internacional, Sevilla. Sevilla, Instituto Andaluz de Administración Pública, 2010, pp. 81-92. P. 91.

${ }^{21} \quad$ Ibid., p. 87.

22 Ibid., p. 88. 
lo biológico conforma a lo moral, sin que podamos hablar de una biologización de la ética en el sentido más burdo reduccionista ${ }^{23}$. Esto se logra porque en Ellacuría la ética ya inaugura un ámbito de realidad en el que se desarrolla, que no es otro que la historia, como ya sabemos.

La realidad histórica es el ámbito de lo ético como ámbito específicamente humano, en el que se realiza el hombre especie. Hay, por tanto, una suerte de cambio cualitativo en la realidad que en el hombre se traduce en el paso de lo estrictamente biológico a lo histórico, sin que lo biológico sea negado o desaparezca. Es en la historia donde se puede dar lo opcional dentro de los límites y el material que otorga la historia misma, en esa combinación de libertad y determinismo que caracteriza a la actividad humana, a la praxis humana, según Ellacuría.

\section{La Revitalización de la Teoría Crítica en Ignacio Ellacuría}

Si reasumimos de la mano de Ellacuría una teoría crítica, se trataría de indagar comparando lo posible en la realidad con lo conseguido en la realidad. Pero el pensar crítico no es ni una intención abstracta añadida al pensar ni un pensar ejercitado en un nivel de pseudo-concreción. Siempre se relacionan ideas e intenciones con efectos y configuraciones en el mundo. Así, por ejemplo, señala certeramente Héctor Samour parafraseando a Ellacuría: «afirmar que se quiere la libertad, el amor, etc., pero sin poner las condiciones que los hagan efectivos para todos en una comunidad determinada o en la humanidad misma, es una mistificación que impide que los seres humanos no sean lo que se dice que deben ser» ${ }^{24}$.

Señala el profesor Samour que la concepción ellacuriana de la historia permite un pensamiento crítico y liberador que corrige aquello que se achaca a las filosofías tradicionales de la historia. Las críticas a la filosofía de la historia, dice, se vinculan con el cuestionamiento al cogito cartesiano con su visión supuestamente privilegiada del todo $^{25}$. Así, se recelaría de toda visión global en tanto en cuanto implica un olvido de lo singular, del hombre concreto que se halla disuelto en la facticidad de un mundo de la vida que impide precisamente la obtención de un punto de vista externo sobre la realidad. Se aboga, pues, por la historia concreta, el presente real y lo contingente de todo pensar. En estas corrientes de tipo postmoderno se incluye desde el vitalismo nietzscheano, a la fenomenología de Heidegger, la hermenéutica (Gadamer) o el neopragmatismo (Rorty). La desventaja, sin embargo, señala Samour, que podemos atribuir a estas corrientes críticas con toda concepción fuerte de la historia (filosofía de la historia) que fundamente una emancipación en un sentido ilustrado, es que, precisamente, no pueden fundamentar con claridad un proyecto liberador. Aunque Samour admite, desde luego, ciertas deficiencias que nadie discute en el proyecto ilustrado original (formalismo que encubre un sesgo material en el pensamiento universalista).

Frente a estos extremos (postmodernidad y modernidad fuerte de la filosofía de la historia) sí existe la posibilidad de un deber ser que haga de rasero en los análisis que

23 Ibíd., pp. 88-89.

24 SAmour, H. «La filosofía de Ignacio Ellacuría ante los desafíos actuales», en SENENT de Frutos, J. A. y Mora, J. (dirs.) Ignacio Ellacuría 20 años después. Actas del Congreso Internacional. Sevilla, Instituto Andaluz de Administración Pública, 2010, pp. 37-60. P. 57.

25 Ibid., pp. 43-44. 
emprendamos de la historia, pero de un modo que sí sería aceptable: «El filósofo de la historia ya no puede dedicarse hoy a realizar predicciones sobre el futuro, pero tampoco debe renunciar a realizar valoraciones estimativas acerca del mismo; no puede anunciar lo que será, pero sí proponer cómo debiera ser o, en todo caso, cómo no debiera ser jamás $»^{26}$. Esto lo cumple excelentemente, indica con acierto, la filosofía de la realidad histórica de Ignacio Ellacuría. Recordemos que supone una concepción abierta y en absoluto teleológica de la historia, sin corsés metafísicos, porque la historia es una estructura compleja y dinámica, muy plural, que se mueve por delante, podríamos decir, de todo pensamiento de la misma (de nuevo el realismo zubiriano). Hay un conjunto de opciones que desatan dinamismos que se van objetivando en las estructuras históricas. La historia es, en este sentido, una praxis primordial limitada y posibilitada, al mismo tiempo, en cuanto que es material y estructural. Así pues, la historia es praxis y estructura. Nada más. Esto implica una negación evidente por parte de Ellacuría de toda mitología del futuro o ideología del progreso ascendente como elementos metafísicos propios de concepciones idealistas y también presentes en concepciones materialistas (determinados marxismos, por ejemplo).

Nos interesa en grado sumo destacar aquí que el planteamiento ellacuriano da pie a una crítica a Heidegger. Cito al profesor Samour: «Basado en esta concepción [de la realidad histórica], Ellacuría también puede criticar a Heidegger quien reduce el dinamismo histórico a la dimensión existenciaria del Dasein, a un sentido que es necesario comprender. En la historia no se transmiten primariamente sentidos, sino formas de estar en la realidad como posibilidades de vida, sobre las cuales se funda cualquier sentido. Ciertamente es importante indagar sobre el sentido de las acciones humanas e históricas. Pero lo importante es entender que el sentido está radicado en la realidad y no al revés. El sistema de posibilidades transmitido en tradición no es sentido, sino realidad en condición, momento real de la vida real de los individuos y los grupos humanos» ${ }^{27}$.

Asimismo, la historia es posibilidades que se apropian, no potencialidades que florecen. Las potencialidades no varían nunca. Lo que sí marca el curso de la historia son las distintas capacidades y posibilidades que se van poseyendo. No hay, por tanto, un evolucionismo calcado de lo biológico al plano de la historia. Y tampoco es la historia ni maduración ni desvelación ${ }^{28}$. Prevalece, por tanto, la apertura del futuro sin que haya guiones preestablecidos en el devenir histórico y, en esto sí influye una mirada que atiende a lo biológico, hay una pluralidad esencial en la historia: «Dado que el sujeto de la historia en la visión ellacuriana es la especie humana, desaparece toda posibilidad de apelar a un único sujeto ontológico trascendente y se abre, por consiguiente, la posibilidad de multiplicar los temas (género, cultura, educación, etnia, identidad, medioambiente, identidad sexual) y los sujetos de la acción política liberadora $(. ..) »^{29}$. Y de igual forma se niega, con lo que creo que se contesta a muchas de las críticas postmodernas, todo punto de vista privilegiado y externo que señale en sentido absoluto y abstracto lo correcto y lo desviado. Sin embargo esto no impide que se pueda desarrollar, frente a las filosofías postmodernas, un proyecto crítico y emancipador.

$26 \quad$ Ibid., p. 45.

27 Ibíd., pp. 46-47.

$28 \quad$ Ibíd., p. 47

29 Ibid., p. 48. 
Desde el trasfondo zubiriano de índole materialista resulta imposible de hecho un pensar abstracto y elevado sobre la realidad, como si existiera una suerte de radical autonomía de la razón y de la teoría. Dice Samour: «Desde la perspectiva de una inteligencia sentiente, el logos y la razón no flotan sobre sí mismos, la actividad cognoscitiva está radicada primariamente en la necesidad biológica de hacerse cargo de la realidad y por lo tanto es activada por la realidad misma aprehendida sentientemente ${ }^{30}$. Así ocurre con toda actividad intelectiva incluso cuando resulta aparentemente pura o neutra. No puede darse una inteligencia al modo de sustancia, con sustantividad y autonomía, sino que siempre albergaría la inteligencia un carácter relativo a lo que es pensado. "[la inteligencia] siempre está condicionada y determinada por la realidad física total del ser humano en su enfrentamiento activo-sentiente con la realidad ${ }^{31}$. Esto significa que la inteligencia ostenta un carácter material que resulta imposible eludir, aun en el ejercicio de los más altos y «espirituales» vuelos de la razón. La inteligencia permanece siempre ligada al mundo y es constitutivamente mundana.

La inteligencia sentiente, en particular, se opone al formalismo, al logicismo apriorista y a una dialéctica conceptual como es propia de Hegel (idealismo hegeliano). La razón se origina, siempre, en la praxis social e histórica. Señala Samour: «(...) en Ellacuría la actividad teórica tiene una inmediata referencia a la praxis; siempre está condicionada por el mundo histórico en el que se da; y tiene una estricta dimensión social, como momento de una totalidad histórica socialmente condicionada por determinados intereses y por fuerzas sociales» ${ }^{32}$. Añade Samour que «Desde aquí resultan engañosas o quiméricas las propuestas de un pensamiento puramente teórico, formal o transcendental en cualquiera de sus formas, ya sea como la fenomenología, filosofía primera o reflexión transcendental» ${ }^{33}$. Así, a pesar de su relativa autonomía, el pensar del hombre manifiesta siempre un origen y composición materiales, que hay que considerar como ingredientes de cualquier pregunta, incluidas las propias de las filosofías primeras y la preocupación ontológica. Así, la filosofía tiene siempre este carácter secundario, ideológico en un sentido no necesariamente peyorativo semejante al sentido que ostenta en Althusser lo ideológico. De esto se concluye, además, el carácter político de todo pensamiento, aun cuando no pretenda una finalidad práctica o explícitamente política. La inteligencia participa de las limitaciones y de la finitud de todo lo mundano, estando marcada por su procedencia biológica (evolutiva, adaptativa para la especie respecto al medio).

Por tanto, un momento necesario de todo pensar, coherente con lo que estamos exponiendo, es la sospecha acerca de los intereses que pueden subyacer al mismo acerca de su vínculo con el todo social e histórico. Se trata de su autocrítica. «Desde la perspectiva ellacuriana, si la filosofía no asume conscientemente su dependencia de la praxis no solo no puede llegar a convertirse en una reflexión crítica y sistemática de la praxis histórica, sino incluso puede llegar a degradarse, hasta convertirse en una ideologización más, en ser un mero reflejo de la praxis misma» ${ }^{34}$. Esto implica que la filosofía se sepa ubicar en el lugar donde mejor se aprecia la realidad y que, señala Samour, pueda adquirir formas distintas en función de los lugares donde se haya situado, lo que, dice

\footnotetext{
$30 \quad$ Ibid., p. 39.

31 Ídem.

32 Ibid., p. 40.

33 Ídem.

34 Ibid., p. 41.
} 
este autor, podría implicar un vínculo del pensamiento de Ellacuría con el proyecto de la filosofía intercultural de Fornet-Betancourt ${ }^{35}$.

Al pensamiento liberador le mueve, evidentemente, un interés por la liberación, pero este a priori moral puede justificarse epistemológicamente. La necesidad epistemológica de ubicarse en el lugar adecuado (los oprimidos), elude toda acusación de irracionalismo en la medida en que se trata de un dinamismo de la razón que busca comprender la realidad (histórica). La verdad (entendida como esclarecimiento de la realidad histórica) parte de la constatación de una deficiencia en la realidad histórica, de la experiencia de la situación de injusticia. De modo que la razón está entretejida con la praxis. Este tipo de verdad buscada por el filósofo ellacuriano no es la de la ciencia (en sentido restringido), «sino que está aludiendo a alguna dimensión práctica de la verdad, que pueda ponerse en conexión con la liberación humana. Compartir esa experiencia conduce a un nivel de verdad donde razón teórica y razón práctica aún no se han escindido» ${ }^{36}$. Además, precisa J. A. Nicolás: «La verdad no es una cosa o un resultado, sino que es fundamentalmente una tarea histórica de intelección y de discriminación $»^{37}$.

Nicolás alude al carácter de fractura entre lo dado y lo posible que manifiestan los lugares límite de revelación de una verdad histórico-social ${ }^{38}$. Lejos de mantener un apriorismo metodológico, indica Nicolás, hay siempre en Ellacuría una prioridad de la realidad (asunto heredado de Zubiri) y por tanto un carácter experiencial del método para el hallazgo de la verdad sobre la realidad histórica. Así, ha de darse un cierto distanciamiento entre un primer momento experiencial y práxico que ha de ser conectado con un segundo momento de tomar conciencia. Si de esta conexión resulta un ocultamiento se daría una conciencia «falsa». Es así cómo la imagen intelectual de la realidad (pensamiento, conciencia, ideología) puede ser encubridora (ideologizadora) o al contrario (desideologizadora).

\section{LA HISTORIZACIÓN}

La desideologización a la que hemos aludido conlleva una desabstracción de los valores e ideales propugnados, como por ejemplo los Derechos Humanos, y su confrontación con el dato fáctico de si en la actualidad sólo son disfrutados por una pequeña minoría de habitantes del planeta. Así, continuando con el elocuente ejemplo

35 Ibid., p. 42. Vg. Cfr. Fornet-Betancourt, R. «"El mal común”, o de un posible nombre para nuestra época», Dialogo Filosofico, 27:3, 81 (2011), pp. 405-420. Sobre las realizaciones más prácticas o políticas de la filosofía de Ellacuría, además de su obra original, hay trabajos que como el mencionado de Fornet-Betancourt abordan estos aspectos específicamente históricos, "práxicos», de la producción ellacuriana y de sus consecuencias. Vg. Sols J. y Perez, J. C. «El pensamiento de Ignacio Ellacuria acerca de procesos historicos de reconciliacion politica: Analisis de siete conceptos: conflicto, violencia, causa, dialogo, pacificacion, paz, reconciliación», Pensamiento: Revista de Investigacion e Informacion Filosofica, 67, 251 (2011), pp. 103-124.

36 Nicolás, J. A. "La historia como baremo crítico: I. Ellacuría», en Senent de Frutos, J. A. y Mora, J. (dirs.) Ignacio Ellacuría 20 años después. Actas del Congreso Internacional, Sevilla, Instituto Andaluz de Administración Pública, 2010, pp. 61-79. P. 75.

37 Ídem.

38 Ibid., pp. 75-76. 
tan querido por Ellacuría de los Derechos Humanos, señala Romero: «La historización muestra la fractura entre el discurso de defensa de los derechos humanos y la realidad social a la que presuntamente se refiere, la cesura entre el discurso que legitima la estructura social vigente como realización de los derechos humanos y la existencia real de tales derechos en la sociedad. Aspira a dar cuenta, además, de las condiciones que posibilitarían una apropiación colectiva adecuada de tales derechos ${ }^{39}$. La historización es consciente del doble aspecto de plegarse a unos intereses concretos, por un lado, que han de ser enmascarados, por el otro, que ostentan las afirmaciones abstractas acerca de la praxis. Da primacía a la realización, para desvelar las auténticas dinámicas reales e intereses, por encima de la racionalización, que tiende al ocultamiento. La historización puede, sin embargo, aceptar a un nivel conceptual las afirmaciones que dentro de la ideología legitimadora apuntan a verdades o valores deseables. Sin embargo, «lo que hace es separar y mostrar en la praxis histórica cuál es el modo real de convertir en realidad lo que se queda como ideal y de impedir que lo que se pretende llevar a la realidad cobre de hecho realidad» ${ }^{40}$.

La historización, opera verificando en la historia si es verdad y en qué sentido cualquier formulación abstracta. Se trata de poner en la praxis histórica un principio y ver lo que esconde. La invalidación del mismo por el hecho histórico ha de contemplar la extensión e importancia del hecho o situaciones sociales. Se trata de mirar más allá de intenciones y fenómenos, que han de ser explicados atendiendo más allá de las apariencias. Ellacuría critica «el nivel de la pseudo-concreción que desconoce el hecho de que todas las realidades están conectadas formando una unidad y que solo en esa unidad dinámica considerada aparece la verdadera realidad de lo que en la pseudo-concreción se presenta como separado y quieto» ${ }^{41}$.

Señala el profesor Nicolás que «(...) ha de haber una relación comprensiva, en su sentido hermenéuticamente más fuerte, con el sujeto de la liberación, que según Ellacuría no se puede señalar de modo dogmático de una vez por todas y para toda situación histórica ${ }^{42}$. Esto es el primer momento, experiencial, del método ellacuriano de captación de la realidad histórica. Y a continuación, habría de darse, dice Nicolás, una historización de los conceptos. "Se trata de reconstruir los conceptos y valores abstractamente considerados en su dimensión de inserción en la praxis concreta y del efecto

39 Romero, J. M. «I. Ellacuría: una teoría crítica desde América Latina», Revista Internacional de Filosofía Política, 32 (2008), pp. 115-134. P. 130. Para historizar los valores, apela J. M. Romero tanto a Ellacuría como al Nietzsche de la genealogía de la moral. Pero como señala, la crítica genealógica va en efecto mucho más allá, hasta el punto de disolver los valores y mostrar su carácter de instrumentos usados en las luchas entre grupos sociales (Foucault). La crítica genealógica incide con fuerza en lo contingente de los valores y en su carencia de consistencia ontológica. Hay que tener en cuenta entonces que «La distancia entre Ellacuría y la genealogía nietzscheana se ostenta claramente en el hecho de que para el primero la historización de un concepto o un valor no pretende disolver su apariencia abstracta sin más. Pretende desideologizarlo en tanto que concepto o valor abstraído del plano de la praxis social, pero con objeto de promover la realización del núcleo normativo que late en él (su contenido de verdad)» p. 131. Así, existe en Ellacuría la posibilidad de una normatividad que trasciende lo dado, aunque sea intrahistórica e inmanente, a diferencia del planteamiento puramente nietzscheano o postmoderno en los cuales de lo contingente no puede sobrevenir una normatividad fuerte para la crítica social.

40 Ellacuría, I. Cursos universitarios... op. Cit., p. 377.

41 Ibíd., p. 376.

42 Nicolás, J. A. «La historia como baremo... op. Cit. P. 76. 
que de hecho realmente producen en ella» ${ }^{43}$. Así, frente a todo idealismo, se va de la cosa (realidad) a la comprensión de la misma, por lo que hay también una historicidad en el acto de la comprensión que Ellacuría señala y enfatiza a partir de Zubiri. Todo ha de pasar por el tribunal de la historia para que pruebe su verdad. No es que haya algo oculto que desvelar, como en Heidegger, sino que hay una interacción y mutua remodelación constante entre verdad, realidad e historia ${ }^{44}$. La verdad sería, indica Nicolás sintetizando el planteamiento ellacuriano, una tarea y no un mero desvelamiento o despliegue.

Obviamente, en la comprensión de la propia facticidad interviene la ideología. La ideología para Ellacuría era: «(...) una interpretación del mundo social circundante y de nosotros mismos que ilumina la realidad como siendo actualizables en ella unas y no otras posibilidades. La ideología define el perímetro ontológico de lo actualizable como posibilidad propia por un sujeto histórico determinado» ${ }^{45}$. Esto guarda similitudes, como señala Romero, con el planteamiento de Althusser, en el sentido de que en principio no tiene por qué interpretarse lo ideológico en un sentido estrictamente peyorativo. Porque la ideología va a existir siempre como un elemento inextricable del todo histórico-social.

El sentido negativo de la ideología, desde la perspectiva de Ellacuría recibe el nombre de ideologización. Así: «La ideologización delimita el horizonte ontológico de lo actualizable como posibilidad por los sujetos según las necesidades de reproducción del sistema social y no según la satisfacción de las necesidades colectivas, haciendo irrepresentables para los individuos y colectivos posibilidades que su grado de capacitación les permitiría iluminar ${ }^{46}$. Ellacuría ve en la comprensión de los propios condicionamientos una saludable propedéutica para liberarse de esos mismos condicionamientos en la medida de lo posible (en el fondo, el délfico y socrático «conócete a ti mismo»). Para esto, Ellacuría sigue la pista de Marx en su tratamiento y definición de las ideologías, como elementos conceptuales que encubren y legitiman una situación social determinada. Hay en la ideología un evidente componente de no verdad que intenta suplir a la realidad. Por eso, el filósofo debe ser cuidadoso para no hacer ideología en lugar de filosofía, pues pueden confundirse ambas en su pretensión de totalidad y ultimidad. «La ideología sería un sustitutivo de la realidad y un sustitutivo cuya finalidad objetiva sería enmascarar la realidad, especialmente la realidad socio-histórica; ${ }^{47}$.

El planteamiento de Ellacuría parte de asumir la necesidad de que exista un sistema de interpretaciones y valoraciones con las que se defina la relación que establece el individuo con su entorno, con los otros individuos y con el medio natural y social. Parece que sin este conjunto de representaciones, intereses racionalizados, normas justificadas, comportamientos pautados, etc., los hombres no pueden vivir ni desarrollarse. Pero cuando hay una sociedad injustamente estructurada, la ideología funciona como elemento justificador de la situación, porque difícilmente se mantendría la situación sin esta ayuda de lo ideológico, que en este sentido asegura la cohesión y el mantenimiento del todo social injusto. «En este caso la ideología toma ya un sentido peyorativo en el doble sentido de dar una justificación interesada de la misma» ${ }^{48}$. Esto es así porque la ideología siempre cumple la función de dotar de solidez a un sistema social, lo que en el

43 Ibid., p. 77.

$44 \quad$ Ibid., p. 78.

45 Romero, J. M. «I. Ellacuría: una teoría crítica... op. cit., p. 128.

46 Ibid., pp. 128-129.

47 Ellacuría, I. Escritos filosóficos III. San Salvador, UCA Editores, 2001, p. 125.

48 Ellacuría, I. Cursos universitarios... op. cit., p. 370. 
caso de ser desigual o injusto el sistema social, la desigualdad ha de ser disimulada para evitar rupturas en la estructura. Para que la mentira surta efecto debe aparentar ser verdadera, debe ser verosímil todo aquello que dice y señala. Así, la ideología más efectiva, más que simple propaganda o engaño consciente y deliberado, ha de ser un reflejo distorsionado de lo que realmente está ocurriendo, producido en gran medida de manera inconsciente, para que no pueda verse la realidad plena. Así, "podría hablarse entonces de que la sociedad como un todo tiende a autojustificarse y a "racionalizar" su composición y su modo general de actuar; se da entonces un fenómeno especial de inversión en que se ve la realidad desde la imagen que se tiene de ella, una imagen ideal y abstracta, en vez de verse la autoimagen desde lo que es la realidad misma de la sociedad ${ }^{49}$. La ideología evita que sea necesario el reinado del terror y la violencia para asegurar la perduración de una sociedad estructuralmente injusta. Así, se puede vivir en la ilusión de libertad por el hecho de que exista libertad a la hora de comprar cosas que se quieren o que en abstracto gustan o parecen necesarias, aunque en la realidad no respondan a verdaderas necesidades de algunos grupos o sectores sociales (la ilusión consumista).

De todos modos, en la medida que lo ideológico debe aparentar para ser eficaz una cierta autonomía, pueden propugnarse ideas contrarias que entren en discusión con la ideología «oficial». Además, de una sociedad injusta, cree Ellacuría que surgen, tarde o temprano, impugnaciones y denuncias que pueden obrar contrariamente a la ideología oficial. Y también el talante científico puede obrar contra determinadas mitificaciones que operan como ideologías justificadoras ${ }^{50}$.

Ellacuría resalta también la imposibilidad de que una clase dominante que se beneficie de las desigualdades sociales produzca algo más que pura ideología justificadora. El filósofo vasco salvadoreño escoge dos ejemplos: la Iglesia cuando accede al poder y los partidos comunistas cuando, también, acceden al poder. Ambos grupos ostentan, en este sentido, una doble posibilidad: «(...) vemos que no tienen protección real contra el proceso ideologizante, mientras están en el poder o se ven favorecidas por el poder; mientras que, al contrario, desempeñan una fuerte presión desideologizadora, cuando se colocan en la oposición cuando la sociedad está injustamente estructurada» ${ }^{51}$. Así, Ellacuría suscribe la distinción de Mannheim entre ideología y utopía (no escapista) como lo que tiende a negar un orden injusto imperante ${ }^{52}$. En general, la ideología es usa$\mathrm{da}$, consciente o inconscientemente, especialmente por quienes tienen deseos de ocupar lugares de poder, bien sea político o económico. «(...) se ideologiza para mantener el poder y para conseguir el poder, y los que tienen menos facilidades para la ideologización colectiva son aquellos que, preocupados por la justicia y la verdad en la sociedad, no están interesados ni en el poder económico, ni en el poder político, sino en el servicio a quienes no tienen poder y que deben tener un poder social, pero no necesariamente un poder político ${ }^{53}$. Así, los que sufren la injusticia sí pueden ser principio de desideologización. Esto no quiere decir que vayan a ser siempre agentes activos de desideologización, sino que en su realidad objetiva están situados de modo que representan la verdad real del sistema en el que viven, al ser el producto de él. Así, una concientización que venga de ellos mismos y no de fuera, puede hacerles «despertar». Pero esto siempre respondiendo a situaciones históricas concretas.

\footnotetext{
49 Ibíd., pp. 370-371.

50 Ibid., p. 373.

51 Ídem.

52 Ibíd., pp. 373-374.

$53 \quad$ Ibid., p. 374.
} 


\section{UNA TRASCENDENCIA INMANENTE}

La enorme importancia del pensamiento filosófico de Ellacuría estriba, a mi juicio, en que es uno de los autores del siglo xx que elabora una vía de normatividad universal sin que dicha universalización implique la generalización de particularidades concretas y de sus intereses. El remedio aportado por Ellacuría para contrarrestar un posible sesgo epistemológico sería como anticipamos al inicio de este trabajo ubicarse en el lugar donde mejor se manifiesta la verdad acerca de la estructura histórica y política que determinan el pensamiento. Sólo se pueden explicitar las posibilidades de mejora para el hombre dirigiendo la mirada a la propia historia, que es donde pueden hallarse las posibilidades de mejora. Esto constituye un inmanentismo de la crítica frente a los idealismos utopistas. La detección de posibilidades de mejora ha de hacerse con una mirada, ciertamente, dirigida a la realidad histórica, pero también desde la reveladora perspectiva del oprimido. Como señala Ellacuría citado por Romero: «El análisis crítico de la teoría social es (...) trascendente, pero históricamente trascendente. Transcendencia no es aquí sinónimo de ningún idealismo; solamente anuncia la necesidad de separarse críticamente de una concreta realidad para verla, medirla y criticarla desde sus alternativas históricas, desde sus posibilidades reales» ${ }^{54}$. Se trata de una crítica de lo dado desde la cosa misma, "a partir de las posibilidades que ella contiene» ${ }^{55}$. Añade Romero: "Por ello considero que se puede sostener que el tipo de crítica que Ellacuría está explicitando aquí guarda importantes analogías con la concepción de la crítica inmanente de la tradición hegeliano-marxista, para la cual la tarea es iluminar, en y a partir de lo inmanente, lo transcendente intrahistórico» ${ }^{56}$. Coinciden Romero y el profesor Héctor Samour en que la clave de la «teoría crítica» ellacuriana estriba en centrar la crítica en el desfase entre las «posibilidades de gratificación y autorrealización individual y colectivas iluminadas por la subjetividad constituida a partir del nivel de capacitación alcanzado por la época y la realización restringida de las mismas impuesta por la estructura socio-política vigente ${ }^{57}$.

«El criterio normativo de la crítica es así radicalmente intrahistórico: las posibilidades de realización y gratificación iluminadas como actualizables por subjetividades capacitadas a partir de las posibilidades ya históricamente plasmadas en el mundo social circundante de la propia época ${ }^{58}$. Esto es un modo no teleológico, a diferencia de Hegel o Marx, de entender la marcha de la historia. Hay una contingencia y fragilidad en la historia que se subraya desde un pensar similar al de Adorno o Horkheimer por parte de Ellacuría, es decir, desde lo concreto y desde lo periférico y marginal en el curso de la historia que impugna dicho curso y que tiñe de contingencia e incertidumbre, por tanto, al devenir histórico. Esto lo logra Ellacuría siguiendo la senda de una corrección de Marx con Zubiri ${ }^{59}$.

Frente a concepciones teleológicas o idealistas acerca de la historia, aun cuando adopten ropajes supuestamente materialistas (Comte), Ellacuría matiza bastante el

54 Romero, J. M. «I. Ellacuría: una teoría... op. cit., p. 127.

55 Ídem.

56 Ídem.

57 Ídem.

58 Ídem.

59 Gracia, D. «Filosofía práctica», en Senent de Frutos, J. A. y Mora, J. (dirs.) Ignacio Ellacuría 20 años después. Actas del Congreso Internacional. Sevilla, Instituto Andaluz de Administración Pública, 2010, pp. 11-26. Pp. 16-17. 
asunto del posible final de la historia. Descarta determinismos fatalistas que expliquen el avance de la historia en algún sentido. Pero sí hay una evidente progresión en la historia que hoy día ostenta una novedad significativa en relación con edades anteriores. Esta novedad es la señalada por la unificación o mundialización de la historia, su confluencia universal que hoy día nos hace entender la realidad histórica como un hecho mundial. Pero sobre todo, esto ha ido de modo parejo con la capacidad de la propia historia, tecnológica, de suprimirse. Sobre todo aquí tenemos una diferencia considerable respecto a épocas anteriores de la humanidad. Es decir, la posibilidad de un final en el sentido de término de la historia como posibilidad de la propia historia. Este es un problema que concierne a los hombres, más que el también posible pero lejanísimo final cósmico de la humanidad (su extinción «natural»). Sin que nada esté escrito, sí hay una dependencia respecto a lo que pueda ocurrir de las decisiones «libres» de los hombres, que es lo que, frente a todo determinismo metafísico o del tipo que sea, sí va a concretar si la humanidad está próxima a su extinción «suicida» o puede eludir dicha posibilidad por sí misma. Por eso, el filósofo afirma: «Si la amenaza cósmica no es un peligro histórico, sí lo es la amenaza histórica. Y ante esta eventualidad no sólo han de tomarse medidas, asimismo históricas, sino que han de reducirse mucho las presuntas interpretaciones metafísicas de la historia ${ }^{60}$. Así pues, estamos ante un problema estrictamente histórico. «El problema ya no es, por tanto, si la historia podrá ir dominando a la naturaleza, sino si la historia podrá irse dominando a sí misma. La historia tiene, en consecuencia, ante sí el problema del final de la historia, de un modo que nunca antes lo había tenido; lo que en otros tiempos fue cuestión más o menos teológica, hoy es cuestión que está en el más real de los terrenos históricos, y lo que pudo ser cuestión de un pueblo o de un grupo de pueblos es hoy cuestión de la humanidad entera ${ }^{61}$. Así, si ha habido un cambio o «avance» significativo en la historia es que ésta se ha ido manifestando como más capaz, más dueña de sí misma, como dominadora de sí misma cuyo final ha llegado a estar en sus propias manos. «Todo lo utópico que pueda considerarse este planteamiento, dada la actual ordenación económica, apunta, sin embargo, a la relación entre la posibilidad de finalizar la historia y la posibilidad de reconducirla hacia metas más humanas. La posibilidad de finalizar la historia podría convertirse así en la posibilidad para entrar en otra etapa histórica» ${ }^{62}$.

Incide Héctor Samour, como hemos visto que lo hace J. M. Romero, en las conexiones del filósofo de la liberación con concepciones de la primera generación de la Escuela de Frankfurt. Es aquí donde se halla, además, el punto crucial para esgrimir una crítica a las posturas postmodernas escépticas con un proyecto crítico-liberador como el de Ellacuría. Esta crítica fue propugnada por los frankfurtianos y Benjamin ${ }^{63}$, y también consistía, como en el caso de Ellacuría, en descifrar la formación social real con vistas a su reconfiguración desde ella misma y dentro de sus márgenes. Así, el mesianismo de Benjamin era un mesianismo inmanente, cuyas verdades eran extraídas a partir de la interpretación dialéctica de las grietas, fracasos y anhelos expresados en la historia marginalmente (a través de la construcción de constelaciones de sentido). En palabras de Samour: «Se trata, por tanto, de una crítica normativa inmanente, que busca criticar los sistemas sociales contrastándolas con un posible ser-otro, que sirve para hacer evidentes las patologías sociales y las injusticias de dichos sistemas. Pero es una crítica inmanen-

60 Ellacuría, I. Filosofía de la realidad histórica... op. cit., p. 468.

61 Ibíd., p. 470.

62 Ibíd., p. 471.

63 SAmour, H. «La filosofía de Ignacio Ellacuría... op. cit., p. 49. 
te, porque no se trata de un posible ser-otro meramente imaginado o fantaseado, sino de algo radicado en las alternativas reales que ofrece el mismo proceso histórico de las sociedades concretas; es decir, fundado en la propia realidad criticada y fundamentado en la experiencia» ${ }^{64}$. No se trata, por tanto, de utopismo escapista en el sentido de una contraposición externa a lo real diseñada por la imaginación escindida de lo real. El profesor Samour hace una interesante observación acerca de cómo un proyecto crítico y liberador, en el estilo de Ellacuría, no niega la realidad histórica, ya que dicho proyecto es abierto y se apoya en la apertura propia de la historia, que alberga un importante componente de azar e indeterminación, por su propia estructura cuyas posibilidades de reconfiguración son diversas y de cada estructura reconfigurada emanan distintas posibilidades para lo nuevo ${ }^{65}$.

Es la apertura de la historia la que posibilita una salida inmanente de la configuración histórica existente a la realización de la configuración posible. Señala, Samour en este aspecto el parecido del planteamiento inmanentista de la primera Escuela de Frankfurt con el filósofo vasco salvadoreño: «En Ellacuría encontramos una postura similar en relación a la crítica. Se puede decir que su concepción pone las bases para una comprensión de la facticidad y el carácter histórico de la crítica, permitiéndole eludir la referencia a un ideal o parámetros normativos formales universales de carácter trascendental, cuya tendencia es a caer en una peligrosa abstracción incompatible con la inmanencia histórica ${ }^{66}$. El aspecto trascendente de la crítica inmanente de Ellacuría estriba en que «(...) la crítica se transforma en un análisis histórico trascendente, pero no porque juzga y critica desde una instancia suprahistórica ni desde valores absolutos, sino porque intenta separarse críticamente de una concreta realidad para medirla y juzgarla desde sus alternativas históricas, desde sus posibilidades reales ${ }^{67}$. Se trata de identificar las posibilidades de una realidad a partir de ella misma, como pretendía el análisis dialéctico de Benjamin o Adorno ${ }^{68}$.

El criterio normativo de la crítica, extraído de manera inmanente de la propia realidad, es lo que, siguiendo a Zubiri, la propia época «puede dar de sí de cara a una mayor humanización y personalización de los individuos y los colectivos sociales, el cual es alumbrado desde el nivel de capacitación de las subjetividades propio de dicha época ${ }^{69}$. Esto es un percatarse de la grieta existente entre lo posible a partir de la realidad y lo que de hecho llega a ser dicha realidad, la diferencia entre lo posible y lo dado dentro de una misma realidad histórica. Es a partir de esta constatación, que requiere por tanto ver las posibilidades no dadas pero permitidas por la realidad histórica, como se materializa la crítica inmanente de Ellacuría.

En esto también hay una cierta similitud entre los planteamientos zubiriano-ellacuriano y el marxismo en concepciones «cálidas» que podríamos aplicar, salvando ciertas diferencias, también a Lukács. Tanto en Lukács ${ }^{70}$ como en Bloch $^{71}$ puede hablarse de un hallazgo de tendencias reales en el mundo, inmanentes, por las que el mundo manifes-

${ }^{64} \quad$ Ibíd., p. 50.

65 Ibid., p. 48.

66 Ibíd., pp. 50-51.

67 Ibíd., p. 52.

68 Vid. Romero, J. M. Hacia una hermenéutica dialéctica. W. Benjamin, Th. W. Adorno y F. Jameson. Madrid, Síntesis, 2005.

69 SAmour, H. «La filosofía de Ignacio Ellacuría... op. cit., pp. 52-53

70 LukÁcs, G. Historia y consciencia de clase (vol. 1 y 2). Madrid, Trotta 1984.

71 Bloch, E. El principio esperanza [1]. Madrid, Trotta 2004, pp. 268-295. 
taría unas posibilidades o vías de realización, realización que sería la superación de las contradicciones observadas y la escisiones como sujeto-objeto o teoría-praxis. En estos planteamientos críticos, frente a los extremos representados por el postmodernismo y la modernidad fuerte de las filosofías de la historia, tendríamos la posibilidad de un deber ser que haga de rasero en los análisis que emprendamos de la historia, pero de un modo que no supondría un tipo de mirada contemplativa-exterior a la historia. Esto es lo que hemos indicado que cumple cabal y excelentemente la filosofía de la realidad histórica de Ignacio Ellacuría ${ }^{72}$.

\section{LA EDUCACIÓN LIBERADORA}

A partir de lo expuesto a lo largo de los anteriores parágrafos obtendríamos una base teórica para sustentar una concepción liberadora de la educación, como ya han indicado algunos ${ }^{73}$. Desde la opción que según Ellacuría tiene el hombre para decidir el curso de su historia, podríamos concebir la educación precisamente como el proceso que situaría al individuo o a los pueblos en la posibilidad de elegir entre la reproducción de lo dado o de iluminar las posibilidades de mayor justicia y libertad que alberga lo real. Se trata de la posibilidad de una educación para la desideologización. Se le pediría al educador, por ejemplo, que en su conexión con la realidad histórica en la que educa y para la que educa, contribuyera a iluminar lo que dicha realidad puede dar de sí en beneficio de todos.

Debido a su carácter derivado del lugar social que ocupa dentro de ciertas instituciones en las que se inserta su labor, el educador se verá abocado a elegir entre dos amos, como un estigma por el que nace tan ligado a los sufrientes como a quienes generan el sufrimiento. Es esto lo que han resaltado las corrientes críticas o de la resistencia en la pedagogía que oscilan desde el marxismo hasta las teorías de la desescolarización y que constituyen un fenómeno que ha acompañado a la escuela desde el período ilustrado. Todos los intentos de o bien suprimirla o bien rectificar algunos aspectos (Escuela Nueva, Dewey, etc.) corroboran la importancia de este fenómeno de la ambigüedad en cuanto a su función y posibilidades sociales, que acompaña a la escuela. Esta ambigüedad se da por la escisión de lo escolar respecto al resto de lugares y campos sociales que produce por un lado una inconsciente colaboración con el statu quo al tiempo que por otro lado puede permitirse discursos, leyes y pedagogías que hablan como de otro mundo.

72 Samour, H. «El significado de la filosofía...» op.cit., p. 235; Cfr. Nicolas, J. A. «Liberation Philosophy as Critique: Ellacuria», The Xavier Zubiri Review, 11 (2009), pp. 107-118. La importancia que Ellacuría ostenta, en este sentido, dentro del panorama actual de la filosofía (a pesar del lamentablemente carácter fragmentario, inacabado y escaso de su producción filosófica) así como la evidencia de sus implicaciones concretas en el momento presente, son también muy recientemente mostradas por el profesor Samour: SAmour, H. Crítica y liberación. Ellacuría y la realidad histórica contemporánea. Valencia, Universidad Carlos III de Madrid y ADG-N Libros, 2012.

${ }_{73}$ Nino, F. «Filosofía de la educación latinoamericana: una clave intercultural desde Zubiri-Ellacuría», Cuadernos de Filosofía Latinoamericana, 26, 93 (2005), pp. 111-129; Nino, F. «Filosofía de la educación latinoamericana: Educación para una ciudadanía democrática desde Zubiri-Ellacuría», Cuadernos de Filosofía Latinoamericana, 27, 95 (2006), pp. 271-289; Nino, F. «Aproximaciones a la problemática de la filosofía de la educación latinoamericana», Cuadernos de Filosofía Latinoamericana, 28, 96 (2007), pp. 147-159. 
En efecto, en la escuela se vive y manifiesta con suma claridad la tendencia idealista que en ella adquiere la forma de lo que podemos denominar hybris pedagógica, hybris que señaló perfectamente el psicólogo perteneciente a la Escuela de Frankfurt Siegfried Bernfeld ${ }^{74}$. La impotencia de la escuela para conseguir lo que pretende se debe entender de modo paralelo con la impotencia de una filosofía y de una teoría educativa tan escindidas ambas del mundo como la propia institución de la que brotan. En el típico aislamiento de la academia en relación con otros ámbitos de la realidad histórica se constata el fracaso de un proyecto idealista basado en la transformación del mundo mediante bellos discursos y mera educación, mediante mera teoría o pensamiento antepuesto a la realidad.

Ellacuría nos ayuda a fundamentar una educación cuyo resultado podría ser la «personalización» o constitución de lo personal en el hombre, que es lo que en los hombres es capaz de crear realidad optando a partir de la realidad histórica, como hemos señalado en parágrafos anteriores. En este sentido, la educación sería un proceso interactivo y personal más amplio que la socialización, a la cual sin embargo debe incluir necesariamente (lo social está presente en lo personal como argumentan Zubiri o Ellacuría). La socialización proporciona cierta materia (la cultura, los "valores», las creencias, la estructura inercial de relaciones en la que los hombres son meros elementos de un sistema) necesaria para la creación de realidad por parte de los seres humanos, que como hemos señalado anteriormente, crean realidad pero desde una realidad ya constituida que dota de los ingredientes para el futuro.

Hemos de eludir toda concepción que implique que lo educativo es algo así como realización de «ideales», desenvolvimiento, actualización de potencias, utopismo teleológico o voluntarismo del sujeto abstracto. Todo ello implicaría en el fondo una forma de educación nihilizante, negadora de la realidad, imposibilitadora. Cierto es que esto es el cauce por el que transcurre normalmente lo educativo. Lo educativo adquiere generalmente tintes, en este sentido, idealistas (se educa en función de un deber ser sin contar con la realidad).

Por el contrario, para una correcta captación de lo real con el propósito de que la persona o los pueblos extraigan sus posibilidades de ello y elijan consecuentemente creando más realidad (histórica), es necesario que lo educativo desideologice. Lo educativo, en su ambigüedad, puede abrir los ojos a lo que puede ser realidad pero que no se ha concretado aún. Este tomar conciencia al que puede contribuir la educación es ofrecer un tipo de visión que pueda percibir la grieta entre el horizonte de posibilidades y lo dado. Para esto, insistiría Ellacuría, las instituciones educativas habrían de posicionarse en el lugar correcto (con los oprimidos). Así, en un sentido ellacuriano, educar (en su aspecto positivo contrapuesto a la ideologización) sería disponer de la propia realidad, entregar y recibir realidad en lo que supone una activación de hecho y sin inhibiciones u obstáculos de la relacionalidad constituyente del sujeto que se vincula conscientemente a su mundo. Dicho de un modo que puede sonar extraño: enriquecer la existencia, siempre que entendamos este enriquecimiento en estrecha interacción con la realidad histórica, como una maximización de las capacidades y logro de todas las posibilidades materialmente existentes.

Hacer y actuar está ligado al pensamiento, como salvando las distancias queda resaltado en Dewey ${ }^{75}$. Por eso, una inacción (forzada) en el nivel de la praxis conduce a un

74 Bernfeld, S. Sísifo o los límites de la educación, Buenos Aires, Siglo XXI, 1975.

75 Dewey, J. Democracia y educación, Madrid, Morata, 1995. 
pensamiento impotente y fatalista, como en la pedagogía pone de relieve Freire ${ }^{76}$. Toda parálisis social implica una parálisis intelectual y una no captación racional del todo. Es lo que el método de alfabetización freiriano tanto resalta e intenta resolver ${ }^{77}$. Así, también explica el marxismo (el Lukács de Historia y consciencia de clase) el paralizante refugio en la interioridad individualista o la ética privada. Toda transformación exclusivamente ética resulta víctima de esta escisión si se queda en un cambio meramente interiorista.

Desde la perspectiva que estamos exponiendo, el mejor conocimiento de sí significa para el hombre tomar conciencia del vínculo con lo demás (y con los demás). Conocerse el hombre es conocer el mundo. Es este mejor conocimiento el que puede aportar luz acerca de las posibilidades que esconde lo real y que pueden activarse en movimientos revolucionarios; la corrección, que creo que también intuye Freire, del punto de vista del oprimido, o sea, de lo concreto insuperable que sufre lo real y que desborda, en su sufrimiento impugnante, todo intento de abarcarlo conceptualmente (Benjamin, Adorno). Freire, en una línea benjaminiana-adorniana, asume la negatividad de la parte que impugna al todo y que no puede, además, superarse.

La tarea de la teoría de la educación de captar lo educativo desde la realidad implica la adopción de un enfoque materialista. Esto daría la oportunidad de superar la escisión entre teoría y praxis educativa y soslayar el peligro idealista de teorizar en un ámbito contemplativo. El proyecto idealista, en los distintos campos en que se ha aplicado (filosofía, política, historia, teología, pedagogía, sociología e incluso ciencia natural) ha mostrado esta tendencia escapista e ideologizadora, la cual hemos señalado en el presente trabajo que es denunciada por la filosofía de Ellacuría.

\section{8. ¿CONCLUSIÓN? LA INSUPERABLE NEGATIVIDAD}

En síntesis, destaquemos que Ellacuría nos presenta una opción que enfatiza cómo lo bueno es posible en la inmanencia, elaborando una ética material (y política) de la liberación. Otra opción de lucha, más trágica en el sentido de fatum insuperable y por eso con la ambigüedad de todo combatir estoico, sería la ética del segundo Camus. En Camus (La peste, El hombre rebelde) hay una solución al mal estrictamente inmanente que apuesta por los hombres, pero también hay en dicha solución un rescoldo de negatividad insuperable que estigmatiza la existencia de los hombres. Aquí, hace tiempo quise ver una afinidad entre el estoicismo y Camus (en cuanto filosofías de lo contingente) ${ }^{78}$. El estoicismo apunta a una metafísica del eterno retorno, cíclica, frente a la tensión hacia delante propia del marxismo o del cristianismo libre de elementos gnósticos. La concepción de la historia como una superación o transformación constante en el marxismo o el cristianismo aporta una base para la esperanza que no aporta el fatalismo trágico estoico, pero éste, sin embargo, nos previene con acierto de que sí hay un destino que como el de Sísifo se repite cansinamente, a pesar de todos los logros de los hombres: un tipo de perenne fracaso, el hecho de que los logros históricos son a medias, porque to-

76 Freire, P. Pedagogía del oprimido, Madrid, Siglo XXI, 1992.

77 Vid. Ibíd., y Freire, P. La educación como práctica de la libertad, Siglo xxi. Madrid, 1989.

78 SANTos, M. «La filosofía como pedagogía en el Estoicismo tardío romano», Revista Española de Pedagogía, 65, 237 (2007) pp. 317-332. 
dos los proyectos humanos se truncan y se quedan apenas recién nacidos. Es el carácter fragmentario que acarrea siempre la historia, el llanto por lo inacabado que jamás podrá ser restaurado. La liberación y la forma de combatividad de los estoicos paganos (Marco Aurelio, Epicteto, Séneca) partían de este pathos incuestionable. Es lo que en la filosofía marxista introduce Benjamin. Un eterno retorno de lo malo que convierte a lo malo en constante presencia y compañía de los hombres.

Nos venimos a referir a una constante tensión entre dos polos, permanencia de lo malo y superación de lo malo, en la cual se hace, en la cuerda floja, la historia humana. Y podemos desde luego mantenernos en esta tensión agnósticamente como hicieron Benjamin o Camus. Un agnosticismo al que acompaña la sombra de Dios, o anhelo de que las cosas fueran de otro modo o de que hubieran sido mejor para los hombres. Se trata del tiempo mesiánico donde depositar las esperanzas de quienes vieron perdidas todas sus esperanzas. Aunque este deseo alude al mundo, parte del propio mundo y se expresa en términos mundanos, como deseo que es, apunta sin embargo al sueño de otro mundo. Así, algo tan humano, demasiado humano, como el deseo y la esperanza apuntarían a un más allá en el que fácilmente puede sospecharse la sombra del Dios absolutamente trascendente. En cualquier caso, el elemento negativo en la historia actúa como espuelas para el caballo de la historia y ostenta una función inmanente que se ejecuta en la praxis, por mucho que no se agote en ella. Por eso, nada puede permanecer como tal en la historia. En lo positivo, éste es el elemento que nos ayuda a superar las tiranías concretas en el presente. «Hay que dejar espacio al tiempo mesiánico, manteniendo el carácter limitado de toda transformación social y evitando el triunfalismo de las realizaciones históricas, que generan nuevas formas de violencia social» ${ }^{79}$. Interpreto que en este sentido es en el que señala Estrada que «El planteamiento de Benjamin es más radical que el de I. Ellacuría ${ }^{80}$.

Universidad de Granada

Marcos Santos Gómez masantos@ugr.es

[Artículo aprobado para publicación en noviembre de 2013]

79 EstradA, J. A. «De la hermenéutica de sentido a la de la liberación. Interpelaciones a la filosofía y a la teología» en Senent de Frutos, J. A. y Mora, J. (dirs.) Ignacio Ellacuría 20 años después. Actas del Congreso Internacional, Sevilla, Instituto Andaluz de Administración Pública. 2010, pp. 453-475. P. 464.

${ }_{80}$ Ídem. 
